\title{
Self-prescription: brainpower from a bottle
}

$\mathrm{H}$

erbal concoctions. Vitamins. Fish oils. Puzzles. Video games. Deep breathing exercises, coupled with meditation. Mozart sonatas. Hypnosis. Creating an imaginary friend with whom to have profound philosophic debates.

It seems that alternative means of enhancing cognitive skills are all the rage these days.

So why not allow the off-label use of cognitive-enhancing drugs among health care professionals, particularly if augmenting their brainpower improves their capacity to deliver care?

Arguably, it may be no different than enhancing sexual stamina with sildenafil or reducing the incidence of diseases through vaccinations. Some experts, though, believe that the offlabel use of such drugs puts users at risk of physical and mental disorders, particularly as the consequences of longterm use are essentially unknown.

Nevertheless, others believe the benefits may outweigh the risks.

It's an era of cognitive enhancement and may well be a new age of "cosmetic neurology," asserts Dr. Anjan Chatterjee, professor of neurology at the School of Medicine at the University of Pennsylvania in Philadelphia.

But it's not entirely about enhancing physiologies for cosmetic purposes, Chatterjee notes, while arguing that there may be instances in which it might be wise to allow doctors and other professionals to reach for the drug drawer.

"Would you want residents to take medications after nights on call that would make them less likely to make mistakes in caring for patients because of sleep deprivation?" asks Chatterjee, who defines cognitive enhancement as "the ingestion of substances by healthy individuals to augment mental functions such as memory, attention, concentration, wakefulness, intelligence, emotional, and even motor abilities."

"Would you pay more for flights whose pilots were taking a medication

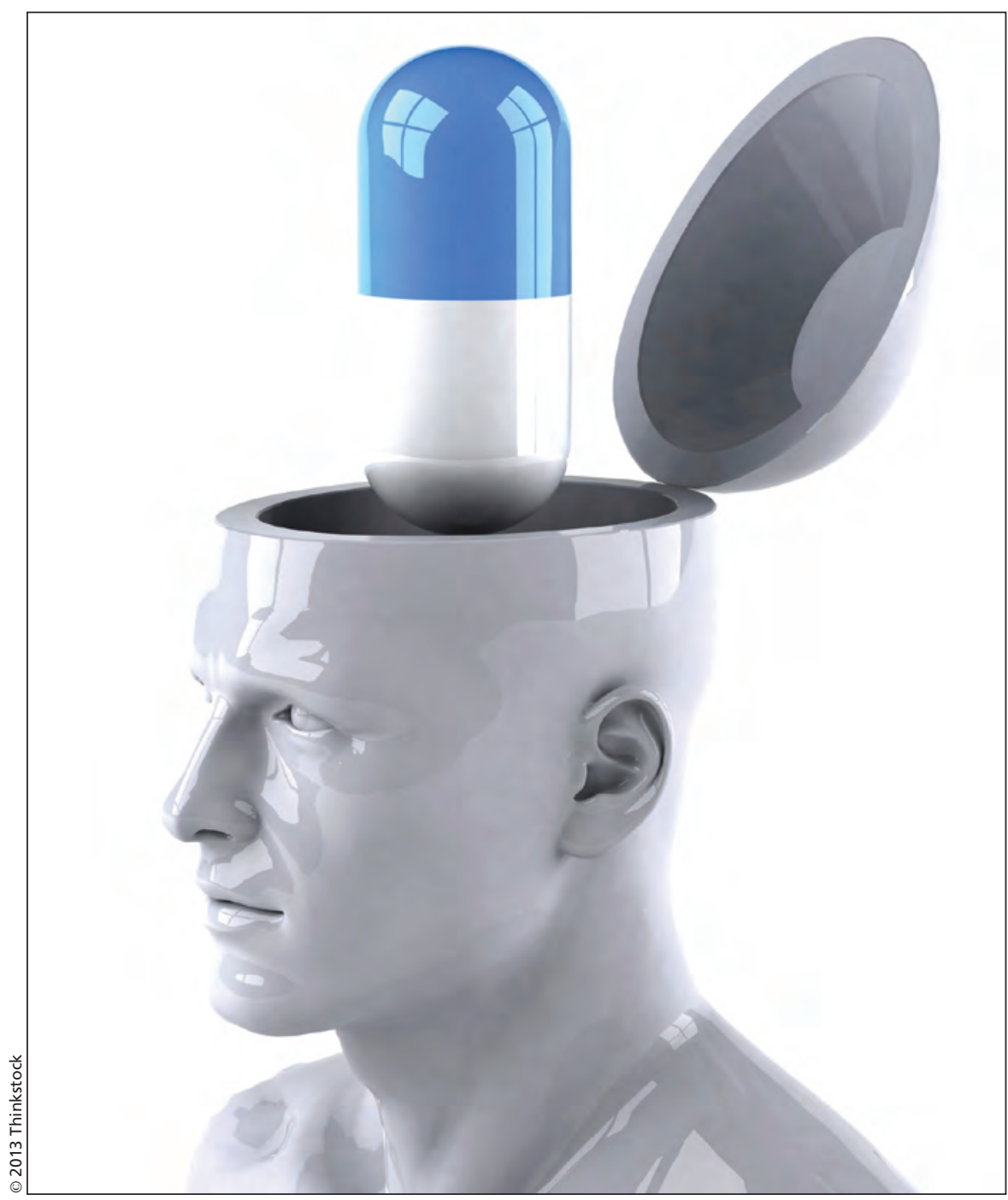

There is no evidence that the use of cognitive enhancers improves clinical competency and it may make sleep-deprived doctors overconfident in their abilities.

that made them react better in emergencies?" he adds. "How much more?"

There's growing interest in the use of cognitive enhancers within the health care profession, adds Dr. Colin Sugden, clinical lecturer in the Department of Surgery and Cancer at Imperial College London in England. "Ever since the serendipitous discovery that drugs used to treat narcolepsy (modafinil) and attention-deficit-hyperactivity disorder (such as methylphenidate) can improve cognition of healthy people, public and scientific interest has grown."
Certainly, a sizable percentage of university and medical students appear to have tapped into the trend. Off-label use of stimulants, including methylphenidate and mixed amphetamine salts, is as high as $25 \%$ at some universities, with an average lifetime prevalence of $6.9 \%$, according to the largest study to date on the issue (Addiction 2005;99: 96-106).

Roughly $10 \%$ of medical students admitted to the off-label use of stimulants, primarily to improve academic performance, according to another 
study (Academic Psychiatry 2010;34: 220-223). Similar results have been found in dental students, with $12.4 \%$ indicating that they used stimulants to bolster concentration levels ( $J$ Dent Educ 2011;75[3]:365-76).

Meanwhile, an unofficial online survey of 1400 scientists in 60 countries indicated that one in five had used drugs for nonmedical reasons to stimulate their focus, concentration or memory (www.nature.com/news/2008 /080409/full/452674a.html).

"The fact is these substances are being used. We would be putting our head in the sand to say that it is not happening," says Chatterjee. "I was having dinner with a group of academic colleagues in San Francisco [California]. Every one of them had tried a cognitive enhancer at some point, from stimulants to antidepressants. None of them were clinically depressed or anxious. And there was no stigma with this - everyone was just interested and curious. ... While I don't know the broad usage amongst all physicians, the trend does seem to indicate that this may be a 'high use' group."

"The American Academy of Neurology has official guidelines on the use of cognitive enhancers. They did not think it was intrinsically bad to be doing it," he adds. "I think it all comes down to context of use. If cognitive enhancers are being used to offset long work hours in doctors, and as a way to make physicians work longer, then I think that is potentially a very bad situation. On the other hand, if doctors want to use [them] for enhancement, similar to how caffeine is used today, then I agree, why not?"

But are doctors actually performing at a higher level when they're pumped up with cognitive enhancers?

The evidence is inconclusive.

Preliminary data from two randomized controlled trials of modafinil found that use of the drug among sleepdeprived doctors may reduce post-call fatigue, while decreasing impulsivity, increasing working memory and enhancing planning ability (Acad Emerg Med 2006;13:158-65 and Ann Surg 2012; 255:222-7). "I would hypothesize that having a greater working memory for example would help physicians perform better, and perhaps even reduce medical error - but this still is yet to be determined and warrants further study," says Sugden, author of the latter study.

The studies did not establish that use of the drugs improves clinical competency, but did indicate their use made sleep-deprived doctors overconfident in their abilities.

That and other unknown effects worry Dr. Serge Gauthier, director of the Alzheimer's Disease Research Unit decide what they want to do to make themselves look and feel better. Cosmetic neurology is no different."

Equally problematic is the potential impact on prescribing patterns. While most physicians are uncomfortable with the notion of prescribing drugs to enhance cognitive abilities in healthy individuals (PLoS One 2010 5;12; e14322), will docs who themselves take the drugs be more inclined to write the script for their patients?

\section{"If doctors want to use [them] for enhancement, similar to how caffeine is used today, then I agree, why not?" - Dr. Arjan Chatterjee}

and professor of neurology, neurosurgery, psychiatry and medicine at McGill University in Montréal, Quebec. The "long-term side effects, particularly of chronic use, are totally unknown. I'd rather give my residents the day off than encourage them to take drugs."

Other concerns include the possibility that the use of cognitive enhancers amongst physicians may be a proxy for other risky behaviour. Stimulant users from college populations have been found to be significantly more likely to use alcohol, tobacco, marijuana, ecstasy and cocaine, or engage in other risky behaviours such as drunk driving (Addiction 2005; 99: 96-106).

Chatterjee, though, argues that such calculations of harm are "tricky" as they don't include calculations of benefit, such as improved clinical competency.

And the likelihood of engaging in other risky behaviours is a correlation that "will fall away with time," he says. "Early adopters of any new practice are always risk takers. So this correlation is not surprising. A strong parallel can be drawn to cosmetic surgery. In early days, there was a concern, particularly among women, that the desire for cosmetic surgery was masking real psychological problems, such as selfesteem issues, depression, etcetera. However, over time, this link has become less and less robust. And now people view it as normal and as an expression of agency and their right to
Chatterjee believes that's likely. "When cosmetic surgery first emerged around World War I, there were all types of reluctances and hesitancies, but over time, acceptance has changed dramatically. A couple years ago, 12 million cosmetic procedures were completed over the course of the year in the United States. It's not just for young starlets in Hollywood anymore. Cosmetic surgery cuts across gender, socioeconomic status, etcetera. If that trajectory serves a historical precedent, something similar will happen with cosmetic neurology. Not everyone will use the substances, but some will."

Gauthier finds that comparison disturbing. "Taking drugs is not the same as cosmetic surgery, because there are potential irreversible and unknown effects to the brain, especially chronic use of 'cognitive enhancers.' The risks of cosmetic surgery are known. There are scars, recovery post-op complications, etcetera."

The cognitive genie may be out of the bottle, though, which makes it incumbent that measures to promote appropriate use are developed.

"It is better to regulate and having guidelines rather than saying that the practice of cognitive enhancement is not acceptable based on philosophical or ethical grounds," Gauthier says. Paul Kudlow, CMAJ

CMAJ 2013. DOI:10.1503/cmaj.109-4382 